\title{
Want to Improve Public Health Access? Let's Start with the Basics: Measuring Efficiency Correctly
}

\author{
Antony Andrews ${ }^{1}$ \\ Published online: 3 April 2020 \\ (c) The Author(s) 2020
}

Across developed countries, rising healthcare costs are a significant challenge for government budgets and a motivation for persuading policymakers to consider ways of reducing inefficiency and increasing productivity. Government expenditures in the healthcare system face severe consequences due to inefficiency, including lower health outcomes and larger unmet population needs [1]. Since the early application of the efficiency measurement technique by Nunamaker [2], which measured the technical efficiency of hospitals in Wisconsin, the analysis of hospital efficiencies has gained considerable momentum. Currently, a vast array of studies uses varying sophistication of econometric methodologies to determine levels of healthcare efficiency. Comprehensive reviews of health care efficiency studies by Hussey et al. [3], Hollingsworth and Peacock [1], and Jacobs et al. [4] identify data envelopment analysis (DEA) and stochastic frontier analysis (SFA) as the dominant methodologies in the literature.

DEA and SFA belong to a class of methodologies using the economic theory of production to measure the performance of a healthcare provider against the so-called 'efficient frontier', determined by the most efficient healthcare providers. In other words, healthcare services are products generated in a production process that uses healthcare inputs in the form of labour, capital, and other intermediaries. The most efficient healthcare provider will use the least amount of inputs to provide a given number of healthcare services. The efficient frontiers are constructed based on the fundamental assumption that healthcare providers, like other manufacturing agents, can reduce or increase their inputs depending on their particular demand for healthcare services. However, this assumption in healthcare production function may not hold, for two reasons. First, the demand for

Antony Andrews

antony.andrews@aut.ac.nz

1 School of Economics, Auckland University of Technology, 120 Mayoral Drive, 1010 Auckland, New Zealand healthcare services cannot always be predicted with enough accuracy, and, as a result, healthcare providers are bound to operate with excess capacity. Second, the presence of excess capacity suggests that healthcare providers cannot readily alter their level of inputs in the pursuit of greater efficiency, leading to rigidities in the adjustment of healthcare inputs. Several studies [5-8] show that there is a substantial excess inpatient capacity among hospitals, with one study by the American Hospital Association [9] approximating the occupancy rates to be as low as $63 \%$ in American hospitals. Moreover, given the highly regulated operating environment and the prevalence of public finances as a key source of healthcare services in most developed countries [4], healthcare providers are often required to maintain a reserve or standby capacity to meet unforeseen health needs $[5,10]$; for example, the recent COVID-19 pandemic.

The existence of rigidity in healthcare inputs suggests that inefficiency among healthcare providers will persist through time, and, as a result, healthcare providers will always have a level of inefficiency with them. Therefore, each healthcare provider should only be benchmarked against their equilibrium level of inefficiency to obtain an unbiased measure of efficiency. To date, in the healthcare literature, only the study by Colombi et al. [11] incorporated the persistent nature of inefficiency for 133 Italian hospitals. Nevertheless, this analysis excluded the concept of rigidities in altering inputs, and linked persistence to technical shortcomings and ineffective organisational structure.

It is not argued that using economic production theory to calculate healthcare efficiency is wrong; however, it is concerning that given tremendous progress in econometric and statistical modelling over the past three decades, traditional economic models are still arbitrarily applied without taking into account the complexities, such as excess capacity and rigidity, associated with healthcare inputs that are inherent in the provision of healthcare services. The existence of excess capacity indicates that there is a long-run equilibrium level of inefficiency that will persist over time for each healthcare 
unit. This long-run inefficiency level must be considered when healthcare providers are benchmarked against each other.

The World Health Organization's healthcare efficiency report [12] states "... while the desire for greater efficiency motivates decision-making, routine use of efficiency metrics to guide these decisions is severely lacking." Therefore, a theoretical model must be suitably modified and should make sense in its application to real-world issues in order to influence policymakers. In a highly regulated sector such as healthcare, where resources cannot be changed instantly, surplus capacity will exist. Productivity and efficiency measures that ignore this critical issue make little practical sense, let alone affect policymakers' decisions. The critical question for operations researchers and economists will be: How should conventional efficiency measurement techniques be adapted to ensure that they can be reasonably applied to healthcare? Perhaps a good starting point can be the incorporation of excess capacity.

\section{Compliance with Ethical Standards}

Funding This commentary received no funding.

Conflict of interest Antony Andrews has no conflicts of interest to declare.

Open Access This article is licensed under a Creative Commons Attribution-NonCommercial 4.0 International License, which permits any non-commercial use, sharing, adaptation, distribution and reproduction in any medium or format, as long as you give appropriate credit to the original author(s) and the source, provide a link to the Creative Commons licence, and indicate if changes were made. The images or other third party material in this article are included in the article's Creative Commons licence, unless indicated otherwise in a credit line to the material. If material is not included in the article's Creative Commons licence and your intended use is not permitted by statutory regulation or exceeds the permitted use, you will need to obtain permission directly from the copyright holder.To view a copy of this licence, visit http://creativecommons.org/licenses/by-nc/4.0/.

\section{References}

1. Hollingsworth B, Peacock S. Efficiency measurement in health and health care. New York: Routledge; 2008.

2. Nunamaker TR. Measuring routine nursing service efficiency: a comparison of cost per patient day and data envelopment analysis models. Health Serv Res. 1983;18(2 Pt 1):183-208.

3. Hussey PS, De Vries H, Romley J, Wang MC, Chen SS, Shekelle PG, et al. A systematic review of health care efficiency measures. Health Serv Res. 2009;44(3):784-805. https://doi.org/10.111 1/j.1475-6773.2008.00942.x.

4. Jacobs R, Smith PC, Street A. Measuring efficiency in health care: analytic techniques and health policy. Cambridge: Cambridge University Press; 2006.

5. Friedman B. Commentary: excess capacity, a commentary on markets, regulation, and values. Health Serv Res. 1999;33(6):1669-82.

6. Gloria JB, Linda RB, Jessica HM, Sylvia K. The transition from excess capacity to strained capacity in US Hospitals. Milbank Q. 2006;84(2):273.

7. Green LV. How many hospital beds? INQUIRY J Health Care Organ Provis Financ. 2002;39(4):400-12. https://doi.org/10.5034/ inquiryjrnl_39.4.400.

8. Madden CW. Excess capacity: markets regulation, and values. Health Serv Res. 1999;33(6):1651-68.

9. American Hospital Association. Hospital statistics. Chicago: HealthForum; 2005.

10. Gaynor M, Anderson GF. Uncertain demand, the structure of hospital costs, and the cost of empty hospital beds. J Health Econ. 1995;14(3):291-317. https://doi.org/10.1016/01676296(95)00004-2.

11. Colombi R, Martini G, Vittadini G. Determinants of transient and persistent hospital efficiency: the case of Italy. Health Econ. 2017;26(Suppl 2):5-22. https://doi.org/10.1002/hec.3557.

12. Cylus J, Papanicolas I, Smith PC. Health system efficiency: how to make measurement matter for policy and management. 2016. http://www.euro.who.int/en/publications/abstracts/health-syste m-efficiency-how-to-make-measurement-matter-for-policy-andmanagement-2016. 